\title{
Test method for evaluating and predicting thermal performance of thermosyphon solar
} domestic hot water system

Kong, Weiqiang; Wang, Zhifeng; Li, Xing; Yuan, Guofeng; Fan, Jianhua; Perers, Bengt; Furbo, Simon

Published in:

Applied Thermal Engineering

Link to article, DOI:

10.1016/j.applthermaleng.2018.09.086

Publication date:

2019

Document Version

Peer reviewed version

Link back to DTU Orbit

Citation (APA):

Kong, W., Wang, Z., Li, X., Yuan, G., Fan, J., Perers, B., \& Furbo, S. (2019). Test method for evaluating and predicting thermal performance of thermosyphon solar domestic hot water system. Applied Thermal Engineering, 146, 12-20. https://doi.org/10.1016/i.applthermaleng.2018.09.086

\section{General rights}

Copyright and moral rights for the publications made accessible in the public portal are retained by the authors and/or other copyright owners and it is a condition of accessing publications that users recognise and abide by the legal requirements associated with these rights.

- Users may download and print one copy of any publication from the public portal for the purpose of private study or research.

- You may not further distribute the material or use it for any profit-making activity or commercial gain

- You may freely distribute the URL identifying the publication in the public portal 
1 Test method for evaluating and predicting thermal performance of thermosyphon solar domestic hot water system

Weiqiang Kong ${ }^{\mathrm{a}}$, Zhifeng Wang ${ }^{\mathrm{b},{ }^{*}}$, Xing $\mathrm{Li}^{\mathrm{b}}$, Guofeng Yuan ${ }^{\mathrm{b}}$, Jianhua Fan ${ }^{\mathrm{a}}$, Bengt Perers ${ }^{\mathrm{a}}$ and Simon Furbo ${ }^{\mathrm{a}}$

${ }^{a}$ Department of Civil Engineering, Technical University of Denmark, Brovej, DK-2880 Kgs. Lyngby, Denmark

${ }^{b}$ Key Laboratory of Solar Thermal Energy and Photovoltaic System, Institute of Electrical Engineering,

Chinese Academy of Sciences, Beijing 100190, China

*Corresponding author: Zhifeng Wang

8

\section{Abstract}

A test method for evaluating and predicting the thermal performance of thermosyphon Solar Domestic Hot Water (SDHW) system was proposed. The evaluating mathematical model of SDHW system was developed based on the two-node theory - a SDHW system was divided into the solid part and the fluid part. By combining the dynamic energy conservation equations of the solid part and the fluid part, the evaluating mathematical model of SDHW system was derived. The model parameters have clear physical meaning which can be used to evaluate the SDHW systems. The evaluating mathematical model was further processed by using the Laplace transformation technique and the predicting mathematical model was then derived. The predicting model can be used to predict the thermal performance of SDHW system for short and long term period with flexible draw off load conditions. The experimental method was designed and experiments were carried out to validate the test method. The measured mean fluid temperature in the storage tank was compared to the predicted mean fluid temperature. The annual thermal performance prediction of the system with two draw off load conditions at different daily hot water consumptions was also carried out.

Key words: solar domestic hot water system; thermal performance prediction; Laplace transformation method; thermosyphon solar water heater 


\section{Nomenclature}

$27 A_{a}$

$28 A_{t}$

$29 A_{u}$

$30 \quad c$

$31 \quad F$

$32 \quad F^{\prime}$

$33 U_{L}$

$34 \quad G$

$35 G_{b}$

$36 G_{d}$

$37 \quad h$

$38 \quad K_{b}$

$39 K_{d}$

$40 \quad M$

$41 \quad m$

$42 n$

$43 \quad P$

$44 t$
Aperture area of solar collector $\left(\mathrm{m}^{2}\right)$

Heat transfer area from absorber part to fluid part $\left(\mathrm{m}^{2}\right)$

Heat transmitting surface area of solar collector $\left(\mathrm{m}^{2}\right)$

Specific heat capacity $(J /(\mathrm{kg} \cdot \mathrm{K}))$

Draw off mass fluid rate per collector aperture area $\left(\mathrm{kg} /\left(\mathrm{s} \cdot \mathrm{m}^{2}\right)\right)$

Collector efficiency factor (-)

Collector overall loss coefficient $\left(W /\left(m^{2} \cdot K\right)\right)$

Total solar irradiance $\left(\mathrm{W} / \mathrm{m}^{2}\right)$

Beam irradiance $\left(\mathrm{W} / \mathrm{m}^{2}\right)$

Diffuse solar irradiance $\left(\mathrm{W} / \mathrm{m}^{2}\right)$

Heat convection coefficient $W /\left(m^{2} \cdot K\right)$

Incidence angle modifier for beam irradiance (-)

Incidence angle modifier for diffuse radiation (-)

$\operatorname{Mass}(k g)$

Mass per square meters $\left(\mathrm{kg} / \mathrm{m}^{2}\right)$

Number of times

Probability that the distribution of $F_{(1, n-2)}$ is greater than $F$

Time $(s)$ 


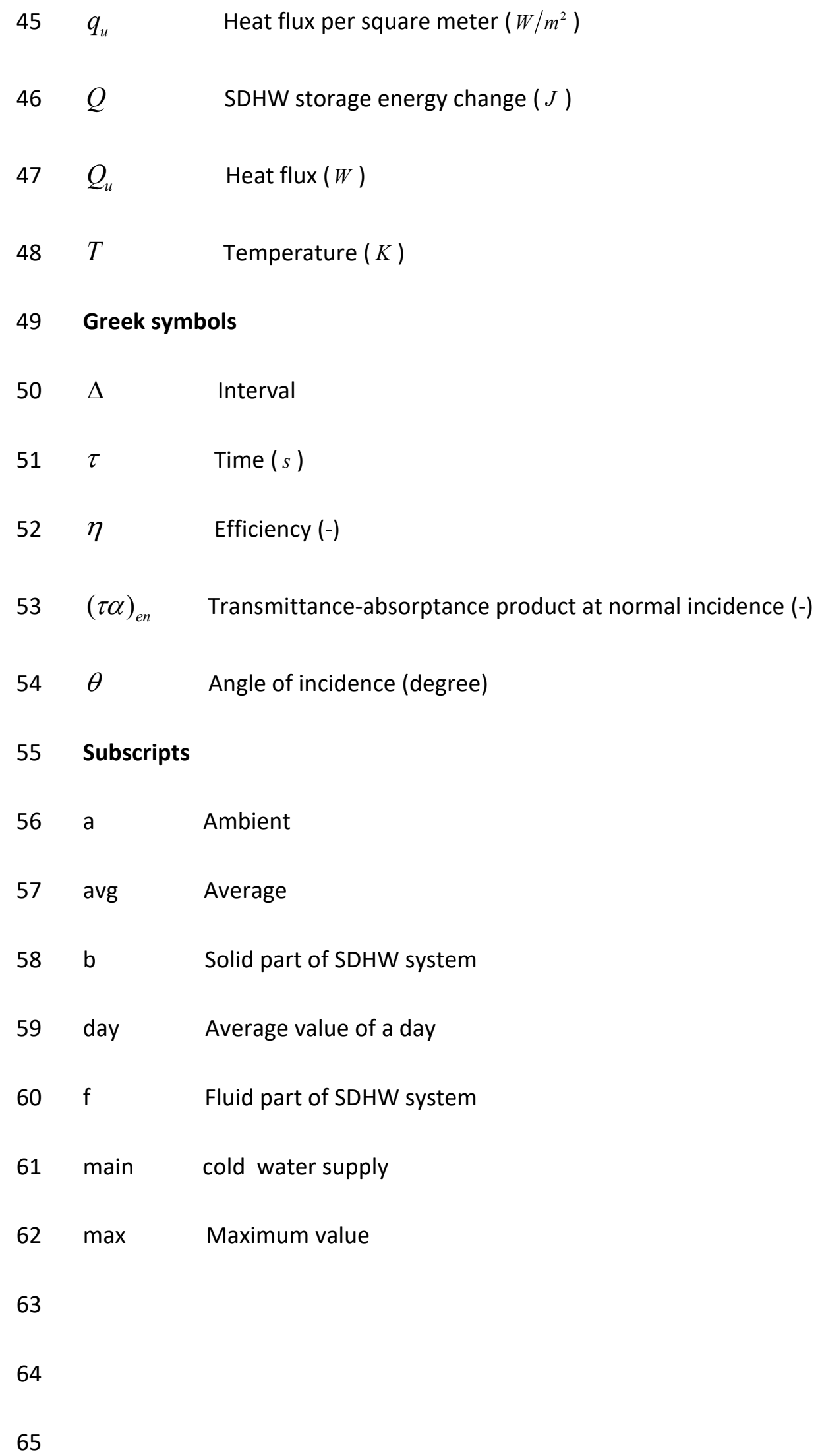




\section{Introduction}

Solar domestic hot water (SDHW) systems [1,2] are now widely used in various aspects of civil area throughout the world. Therefore quality certification and thermal performance evaluation are important both for manufacturers and consumers. Testing is the most important and credible method to rate and evaluate different SDHW systems. Many scholars have developed various testing theories/methods and each of them has its own focus [3-7]. Some methods are used as standards in different countries. Among these different theories/methods, there are two categories of methods that are most commonly used. One category is based on the linear relation between the effective heat gain $Q$ and daily accumulated solar irradiation $H$, such as the International standard ISO 9459-2 [8], the Taiwan standard CNS B7277 [9], Swedish Council Report Document D11 [10], etc. The other category is the dynamic system test (DST) method mainly used in the international standard ISO 9459-5 [11].

\subsection{The Q-H method}

The standard ISO 9459-2 [12,13] is a typical testing method based on the linear relation assumption of the system heat gain $Q$ and the 12 hours solar irradiation $H$. This method considers the SDHW as a black box system which can be seen as a whole heat transfer process. The test requires at least 6 days' one-day test, a short time mixing test and an overnight heat loss test. The one-day test is done independently starting with a tank filled with water at a specific temperature ( $\left.T_{\text {main }}\right)$. The test should be operated for 12 hours: $6 \mathrm{~h}$ before solar noon and $6 \mathrm{~h}$ after, with the weather conditions recorded. Afterwards hot water draw-off with a volume corresponding to at least 3 times of the tank volume is taken with a specific flow rate and a cold water temperature of $T_{\text {main }}$. The effective heat gain of the whole day can be determined by the draw-off process. The one-day test is very strict. Results should be obtained for at least four different days with approximately the same values of ( $\left.T_{\text {a(day) }}-T_{\text {main }}\right)$ and with solar irradiation evenly spread in the range $8 \mathrm{MJ} / \mathrm{m}^{2}$ to $25 \mathrm{MJ} / \mathrm{m}^{2}$. Furthermore two additional days should be tested with ( $T_{a(\text { day) }}-T_{\text {main }}$ ) at least $9 \mathrm{~K}$ above or below the values of ( $T_{a(d a y)}-T_{\text {main }}$ ) obtained for the first four days. The value of ( $\left.T_{a(d a y)}-T_{\text {main }}\right)$ should be in the range from $-5 \mathrm{~K}$ to $+20 \mathrm{~K}$ for each test 
day. Results of the one-day tests are used to obtain the parameters of the $Q-H$ model $\left(a_{1} a_{2} a_{3}\right)$ and the parameters of the $T-H$ model $\left(b_{1} b_{2} b_{3}\right)$, see Eqs. (1) and (2).

$$
Q=a_{1} H+a_{2}\left(T_{a(\text { day })}-T_{\text {main }}\right)+a_{3}
$$

$$
\left(T_{\max }-T_{\text {main }}\right)=b_{1} H+b_{2}\left(T_{a(\text { day })}-T_{\text {main }}\right)+b_{3}
$$

The model parameters $a_{1} a_{2} a_{3}$ and $b_{1} b_{2} b_{3}$ in Eq. (1) and Eq. (2) do not have clear physical meaning. To some extent, the parameters can be explained as follows: $a_{1}$ represents the ability of SDHW system to gain heat from daily irradiation, similar to the maximum efficiency of solar collector panel; $a_{2}$ reflects the system's ability to unify the initial water temperature and the ambient temperature, similar to the heat loss coefficient of solar collector; $a_{3}$ represents the heat capacity of the system's solid part. The model parameters $b_{1} b_{2} b_{3}$ also have similar meaning. Clearly, these model parameters can't rate different SDHW systems in an explicit way.

The mixing test requires that the tank should be preconditioned by hot water with temperature above $60^{\circ} \mathrm{C}$. The collector should be shielded from the sun. A draw-off test is taken the same as the one-day test. The aim of the mixing test is to obtain a normalized drawoff profile used for calculating the long term performance and to determine a parameter expressing the degree of stratification in the tank.

The overnight test is carried out to determine the heat loss coefficient of the storage tank. The initial water in the storage tank should also be preconditioned to a uniform temperature above $60^{\circ} \mathrm{C}$. After cooling period from 12 to 24 hours, the final mean temperature of tank water, the time duration and the average ambient air temperature during the test are recorded and used to determine the overnight heat loss coefficient.

With the model parameters, the draw-off profile of one-day test and the mixing test and the overnight heat loss coefficient determined by the tests, thermal performances of the SDHW system can be calculated day by day based on the weather condition and water load profile. The long term thermal performance of the SDHW system can be estimated by considering the daily energy gain, the overnight heat loss and the previous day's condition. 
The aim of the Taiwan standard CNS B7277 $[13,14]$ is to provide a rating method for thermal performance of thermosyphon SDHW system. The mathematical model uses the efficiency equation of a solar collector for reference, see Eq. (3). Eq. (1) is same as Eq. (3), if $a_{3}$ in Eq. (1) is set to zero for system operating under a steady state condition. $\eta_{0}$ is related to the solar energy absorption efficiency of the collector and $U_{s}$ stands for the heat loss from the system to the ambient. It was found that $U_{s}$ may have larger uncertainty and $\eta_{0}, U_{s}$ can be varied by changing the system designs with various $M / A_{c}$ ratios. $M$ is total mass of water in thermosypon SDHW system and $A_{c}$ is the collector area. Hung [14] proposed an improved method by solely selecting $\eta_{0}$ for performance rating and its value would not depend on $M / A_{c}$ ratio. Then a heat loss test is carried out to obtain a cooling time constant instead of $U_{s}$.

$$
\eta=\eta_{0}-U_{s}\left(T_{\text {main }}-T_{a(\text { day })}\right) / H
$$

The ISO 9459-2 method can be used for long term performance prediction. But the test condition is very strict and the test period is expected to be very long. In addition, the method cannot be used to evaluate different SDHW systems based on the model parameters. The mathematical model is simple which does not describe the complicated heat transfer process in the system during test. The normalized draw-off profile is also roughly divided into two conditions. One is used for daily irradiation in the range of $9 \mathrm{MJ} / \mathrm{m}^{2}-16 \mathrm{MJ} / \mathrm{m}^{2}$ and the other for 136 a solar irradiation in the range $16 \mathrm{MJ} / \mathrm{m}^{2}-25 \mathrm{MJ} / \mathrm{m}^{2}$. This may cause large errors in predicting system thermal performance both on daily and long term basis.

The CNS B7277 method can only rate SDHW system with two system parameters. It can't be used to predict daily or long term thermal performance of SDHW system.

\subsection{The dynamic system method}

The standard ISO $9459-5$ describes a SDHW system by a plug flow store model in conjunction with the dynamic system testing method to predict its long term thermal performance. The operation of the SDHW system can be modeled by a partial differential equation [6]. Each term of the equation characteristically represents a certain sub-process of 
145 the system. The aim of this dynamic method is to obtain these characteristic parameters in short time test which are used to predict the system's long term thermal performance.

The daily test contains two specific operation conditions: namely Test A and Test B. Test A needs at least three valid days to perform and is designed to keep the water at the collector inlet cold and test the system performance at high efficiencies while another three valid days are needed for Test $B$ with the condition of hot inlet water temperature aiming to test the system performance at low efficiencies. Another test sequence is needed to determine the system's overall heat loss. The test should be carried out after two consecutive valid Test B days' operation. Afterwards the system is left to cool down naturally with the collector shielded for 36-48 hours.

\subsection{Comparison of the two standard test methods}

Kaloudis [12] reported a quantitative comparison of the $\mathrm{Q}-\mathrm{H}$ test method and the dynamic test method for a SDHW system. A relative error of $21 \%$ between the two results for the specific SDHW system was derived by experiments which showed a large uncertainty of using the two test methods. It is also further concluded that the $\mathrm{Q}-\mathrm{H}$ test method is more beneficial to the manufacturers but needs long time testing while the dynamic test method is more flexible but the needs more demanding in terms of calculation. 
The proposed test method is a preliminary research aiming to develop a simple but accurate

172 mathematical model for evaluating and predicting SDHW system. The thermosyphon SDHW

173 system was theoretically modeled and experimentally verified in this study. The designed experimental method and the calculation process are easily implemented and the results 175 comparison shows satisfactory accuracy.

176

177

178

179

180

181

182

183

184

185

186

187

188

189

190

191

192

193

194

195

196

197

\section{Theory and mathematical model}

The theoretical model of thermosyphon SDHW system was specified in this section. The evaluating and predicting mathematical models were developed respectively. The parameters in the evaluating mathematical model can be determined by experiments which are used to evaluate the SDHW system. The predicting mathematical model is used to predict the thermal performance of SDHW system together with evaluating model parameters and weather data. The experimental method was designed and specified in section 4.

\subsection{Theory and assumption}

A typical evacuated all glass solar hot water system is investigated. It is usually composed of solar collector, storage tank, insulation, frame etc. An example of market product can be seen in Fig. 4 and the working principle of the natural heat convection is simply illustrated in Fig. 1. Therefore a SDHW system is more complex than a single solar collector. However, if the heat transfer of a SDHW system is considered - solar energy is absorbed by solar collector and then transferred to heat storage tank, it is obvious that the heat transfer mechanism of the SDHW system is similar as a single solar collector. Therefore the main assumption is assumed that a thermosyphon SDHW system can be simply seen as a solar collector with large thermal capacity. The large thermal capacity is mainly contributed by the water in the storage tank. Based on the main assumption, the two-node theory [16-19] which is widely used in solar collector testing area can be implemented to analyze the heat transfer process of the SDHW system. According to the two-node theory, a SDHW system is divided into the solid part and the fluid part. The solid part includes the solid components which directly contact the fluid (water in this case) like the solar collector and the storage tank and the solid components which have no direct contact 
198 with the fluid but are influenced by the heat conduction like the insulation and part of the 199 frame. The thermal capacity of the solid part is lumped and referenced to an assumed collector 200 absorber temperature $T_{b}$. The fluid part is the water in the storage tank and in the solar 201 collector. The mean fluid temperature is defined as $T_{f}$.

\subsection{The evaluating mathematical model}

The dynamic energy conservation equation for the solid part of the SDHW system is shown as Eq. (4). The left hand side is the dynamic term which is the instantaneous heat reserved by the solid part. The right hand side of the equation is the heat absorbed from solar irradiance, the heat loss and the heat transferred from the solid part to the fluid part respectively.

$$
M_{b} c_{b} \frac{d T_{b}}{d t}=F^{\prime}(\tau \alpha)_{e n} K_{\theta} A_{a} G-F^{\prime} U_{L} A_{u}\left(T_{f}-T_{a}\right)-h A_{t}\left(T_{b}-T_{f}\right)
$$

The dynamic energy conservation equation for the fluid part of the SDHW system is 212 described as Eq. (5) where $Q_{u}$ is the heat flux obtained by the storage tank.

$$
M_{f} c_{f} \frac{d T_{f}}{d t}=h A_{t}\left(T_{b}-T_{f}\right)=Q u
$$


By substituting Eq. (5) into Eq. (4), Eq. (6) was easily obtained. For the simplicity's sake, the areas used in Eq. (4) and (5) are all set to the collector aperture area $A_{a}$. The error caused by this simplification will be compensated by the model parameters.

$$
m_{f} c_{f} \frac{d T_{f}}{d t}=Q u / A_{a}=F^{\prime}(\tau \alpha)_{e n} K_{\theta} G-F^{\prime} U_{L}\left(T_{f}-T_{a}\right)-m_{b} c_{b} \frac{d T_{b}}{d t}
$$

The absorber temperature $T_{b}$ cannot be easily measured. Therefore the first order differential term $d T_{b} / d t$ is implicit to some extent. But it needs to be known in the calculation. It is found that $d T_{b} / d t$ only plays an important role in the period when the beam irradiance changes rapidly because the absorber is directly heated by the solar irradiance. The influencing period happens in the early morning or at the beginning of experiment, in the late afternoon or at the end of experiments and in the cloudy weather conditions. Therefore the main assumption of the evaluating mathematical model is that by using a model parameter $C_{b}$ convert the unmeasurable term $d T_{b} / d t$ to the measurable term $d G_{b} / d t$. The parameter $C_{b}$ can be determined by experiments. $C_{b}$ is a parameter related to the solid heat capacity and it behaves as the thermal capacity of the system solid part.

$$
m_{b} c_{b} \frac{d T_{b}}{d t}=C_{b} \frac{d G_{b}}{d t}
$$

The final evaluating model is described in Eq. (8). The total solar irradiance should be separated into the beam and diffuse irradiance together with their incident angle modifier.

$$
m_{f} c_{f} \frac{d T_{f}}{d t}=F^{\prime}(\tau \alpha)_{e n} K_{b} G_{b}+F^{\prime}(\tau \alpha)_{e n} K_{d} G_{d}-F^{\prime} U_{L}\left(T_{f}-T_{a}\right)-C_{b} \frac{d G_{b}}{d t}
$$

SDHW systems with evacuated tubular collector (ETC) are more sensitive to sun light incidence angle. In order to get higher precision results for SDHW system with ETC, the beam irradiance was further divided according to the transversal incidence angle with a resolution of for example 10 degree. This treatment was called "dummy variables" in the Multi Linear Regression (MLR) method, also called "extended MLR" method [20]. The final evaluating equation of extended MLR method is shown as follows: 


$$
m_{f} c_{f} \frac{d T_{f}}{d t}=F^{\prime}(\tau \alpha)_{e n} K_{b}(5) G_{b}\left(0^{\circ}-10^{\circ}\right)+F^{\prime}(\tau \alpha)_{e n} K_{b}(15) G_{b}\left(10^{\circ}-20^{\circ}\right)+\cdots \cdots
$$

$$
F^{\prime}(\tau \alpha)_{e n} K_{b}(85) G_{b}\left(80^{\circ}-90^{\circ}\right)+F^{\prime}(\tau \alpha)_{e n} K_{d} G_{d}-F^{\prime} U_{L}\left(T_{f}-T_{a}\right)-C_{b} \frac{d G_{b}}{d t}
$$

The model parameters which will be determined by test are $F^{\prime}(\tau \alpha)_{e n} K_{b}(5) \ldots \ldots F^{\prime}(\tau \alpha)_{e n} K_{b}(85), F^{\prime}(\tau \alpha)_{e n} K_{d}, F^{\prime} U_{L}$, and $C_{b}$. These model parameters can

241 be used to evaluate the thermal performance of SDHW systems.

\subsection{The predicting mathematical model}

Eq. (8) is the governing equation for the model parameter evaluation. Therefore, a whole day testing without draw off is needed. However, in the thermal performance test, draw off operation is necessary no matter with an evening draw off adopted by ISO 9459-2 or several draw offs load profile used by ISO 9459-5. The governing equation with the draw off sub247 process is written as Eq.(10).

$$
m_{f} c_{f} \frac{d T_{f}}{d t}=F^{\prime}(\tau \alpha)_{e n} K_{b} G_{b}+F^{\prime}(\tau \alpha)_{e n} K_{d} G_{d}-F^{\prime} U_{L}\left(T_{f}-T_{a}\right)-C_{b} \frac{d G_{b}}{d t}-F c_{f}\left(T_{f}-T_{\text {main }}\right)
$$

By applying the Laplace transformation process and the reverse process [21] for Eq. (10), the integral equation of the mean fluid temperature in the storage tank can be obtained as Eq. (11). The first order differential term $d G_{b} / d t$ is rewritten as $G_{b}{ }^{\prime}$. The beam irradiance term is not expanded for the purpose of easy-read equation. But it can be expanded for each incidence angle range for extended MLR method as Eq. (9) for ETC collectors in practical use.

255

$$
T_{f}(\tau)=T_{f}(0) \exp \left(-\frac{F^{\prime} U_{L}}{m_{f} c_{f}} t\right)+
$$

$$
\int_{0}^{\tau}\left[\frac{F^{\prime}(\tau a)_{e n} K_{b}}{m_{f} c_{f}} G_{b}(\tau-t)-\frac{C_{b}}{m_{f} c_{f}} G_{b}^{\prime}(\tau-t)+\frac{F^{\prime}(\tau a)_{e n} K_{d}}{m_{f} c_{f}} G_{d}(\tau-t)-\frac{F^{\prime} U_{L}}{m_{f} c_{f}} T_{a}(\tau-t)-\frac{F}{m_{f}} T_{\text {main }}\right] \exp \left(-\frac{F^{\prime} U_{L}}{m_{f} c_{f}} t\right) d t
$$


The predicting model of Eq. (11) has clear physical meaning. During the time period (0- $\tau$ ), the mean fluid temperature in the end $T_{f}(\tau)$ equals to the summation of the initial fluid temperature $T_{f}(0)$ and the accumulative effect of the environmental influence (irradiance, ambient temperature and draw off) each with an exponential term as the weighting factor. The mean fluid temperature is dependent on the environmental conditions, the initial fluid 262 temperature and the model parameters. The cold water supply temperature during draw off is usually constant. Therefore $T_{\text {main }}$ is used.

264

265

266

The integral equation of Eq. (11) has to be discrete for calculation. Assume that in the period from 0 to $\tau_{d} . \tau_{d}$ is divided into $n$ time intervals. Each time interval is $\Delta t$. Therefore $\tau_{d}=n$ $\Delta t$.

The discrete equation is derived as Eq. (12). For simplicity's sake, the beam and diffuse irradiance term were written together. It can be easily separated in practical.

$$
T_{f}\left(\tau_{d}\right)=T_{f}(0) \exp \left(-\frac{F^{\prime} U_{L}}{m_{f} c_{f}} \tau_{d}\right)+
$$

$$
\sum_{k=0}^{n-1}\left[\frac{F^{\prime}(\tau a)_{e n} K_{\theta}}{m_{f} c_{f}} G\left(\tau_{d}-k \Delta t\right)-\frac{C_{b}}{m_{f} c_{f}} G_{b}^{\prime}\left(\tau_{d}-k \Delta t\right)-\frac{F^{\prime} U_{L}}{m_{f} c_{f}} T_{a}\left(\tau_{d}-k \Delta t\right)-\frac{F}{m_{f}} T_{\text {main }}\right] \exp \left(-\frac{F^{\prime} U_{L}}{m_{f} c_{f}} k \Delta t\right) \Delta t
$$

A simple example without draw off process is created for illustrating the calculation method of the discrete equation, see Fig. 2. It shows a typical mean fluid temperature developing profile of a thermosyphon SDHW system in one day. Four points were taken for illustration. Each point represents a mean fluid temperature and the time interval in between is $\Delta t$. So the fluid temperature $T_{f}(3)$ can be calculated as Eq.(13) based on the initial fluid temperature $T_{f}(0)$, the environmental condition $\left(G_{b}, G_{b}{ }^{\prime}, G_{d}, T_{a}\right)$ in each time step and the model parameters. Eq. (12) is a progressive equation therefore the mean fluid temperature at one time step can also be calculated in another way based on the previous mean fluid temperatures step by step, see Eq. (14). 


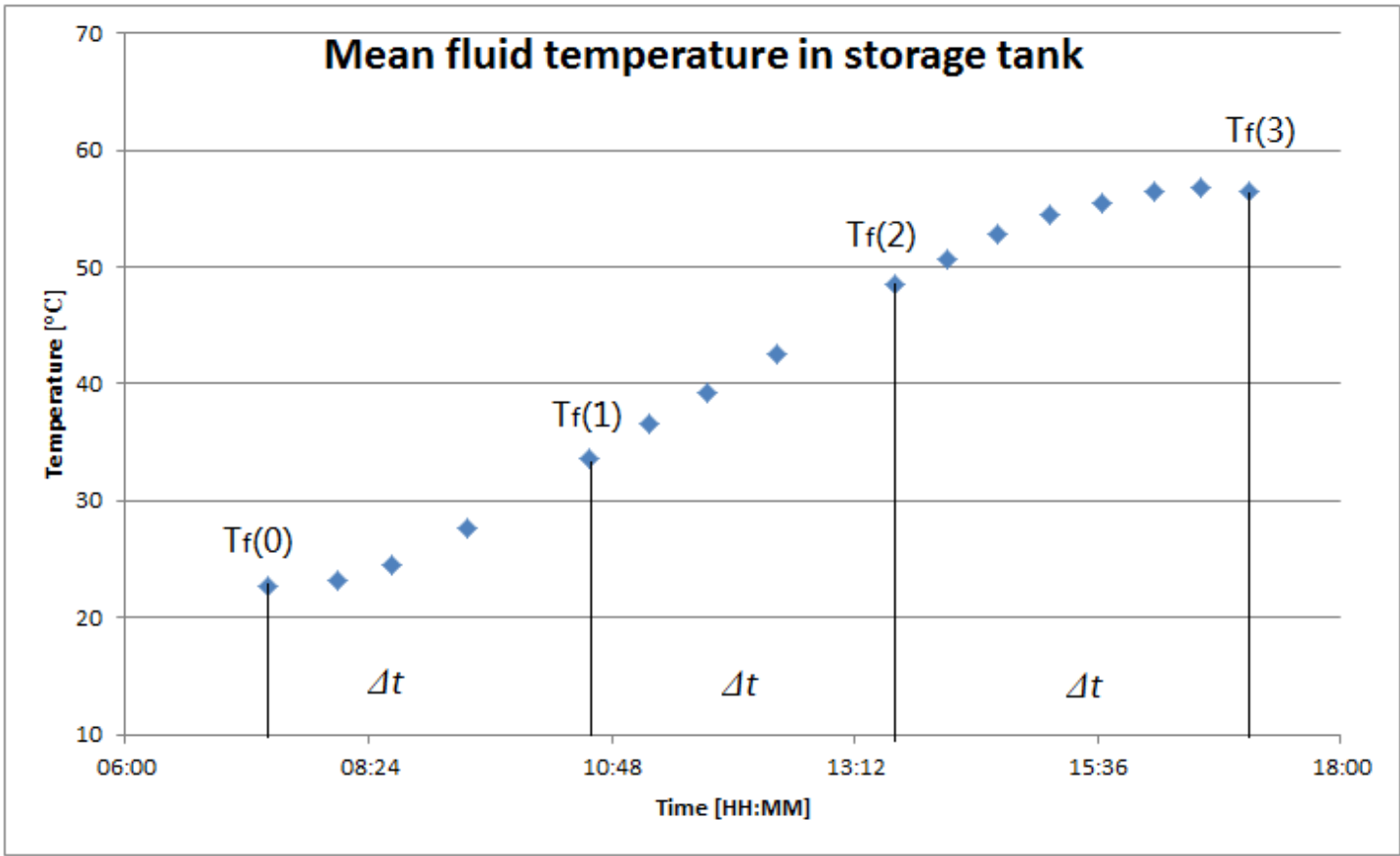

Fig. 2. A typical mean fluid temperature developing profile of a thermosyphon SDHW system in one day

282

$$
\begin{aligned}
& T_{f}(3)=T_{f}(0) \exp \left(-\frac{F^{\prime} U_{L}}{m_{f} c_{f}} 3 \Delta t\right) \\
& +\left[\frac{F^{\prime}(\tau \alpha)_{e n} K_{b}}{m_{f} c_{f}} G_{b}(1)-\frac{C_{b}}{m_{f} c_{f}} G_{b}^{\prime}(1)+\frac{F^{\prime}(\tau \alpha)_{e n} K_{d}}{m_{f} c_{f}} G_{d}(1)-\frac{F^{\prime} U_{L}}{m_{f} c_{f}} T_{a}(1)\right] \exp \left(-\frac{F^{\prime} U_{L}}{m_{f} c_{f}} 2 \Delta t\right) \Delta t
\end{aligned}
$$$$
+\left[\frac{F^{\prime}(\tau \alpha)_{e n} K_{b}}{m_{f} c_{f}} G_{b}(2)-\frac{C_{b}}{m_{f} c_{f}} G_{b}^{\prime}(2)+\frac{F^{\prime}(\tau \alpha)_{e n} K_{d}}{m_{f} c_{f}} G_{d}(2)-\frac{F^{\prime} U_{L}}{m_{f} c_{f}} T_{a}(2)\right] \exp \left(-\frac{F^{\prime} U_{L}}{m_{f} c_{f}} 1 \Delta t\right) \Delta t
$$

$$
+\left[\frac{F^{\prime}(\tau \alpha)_{e n} K_{b}}{m_{f} c_{f}} G_{b}(3)-\frac{C_{b}}{m_{f} c_{f}} G_{b}^{\prime}(3)+\frac{F^{\prime}(\tau \alpha)_{e n} K_{d}}{m_{f} c_{f}} G_{d}(3)-\frac{F^{\prime} U_{L}}{m_{f} c_{f}} T_{a}(3)\right] \exp \left(-\frac{F^{\prime} U_{L}}{m_{f} c_{f}} 0 \Delta t\right) \Delta t
$$

283

$$
T_{f}(1)=T_{f}(0) \exp \left(-\frac{F^{\prime} U_{L}}{m_{f} c_{f}} \Delta t\right)+\left[\frac{F^{\prime}(\tau \alpha)_{e n} K_{b}}{m_{f} c_{f}} G_{b}(1)-\frac{C_{b}}{m_{f} c_{f}} G_{b}^{\prime}(1)+\frac{F^{\prime}(\tau \alpha)_{e n} K_{d}}{m_{f} c_{f}} G_{d}(1)-\frac{F^{\prime} U_{L}}{m_{f} c_{f}} T_{a}(1)\right] \Delta t
$$

284

$$
\begin{aligned}
& T_{f}(2)=T_{f}(1) \exp \left(-\frac{F^{\prime} U_{L}}{m_{f} c_{f}} \Delta t\right)+\left[\frac{F^{\prime}(\tau \alpha)_{e n} K_{b}}{m_{f} c_{f}} G_{b}(2)-\frac{C_{b}}{m_{f} c_{f}} G_{b}^{\prime}(2)+\frac{F^{\prime}(\tau \alpha)_{e n} K_{d}}{m_{f} c_{f}} G_{d}(2)-\frac{F^{\prime} U_{L}}{m_{f} c_{f}} T_{a}(2)\right] \Delta t \\
& T_{f}(3)=T_{f}(2) \exp \left(-\frac{F^{\prime} U_{L}}{m_{f} c_{f}} \Delta t\right)+\left[\frac{F^{\prime}(\tau \alpha)_{e n} K_{b}}{m_{f} c_{f}} G_{b}(3)-\frac{C_{b}}{m_{f} c_{f}} G_{b}^{\prime}(3)+\frac{F^{\prime}(\tau \alpha)_{e n} K_{d}}{m_{f} c_{f}} G_{d}(3)-\frac{F^{\prime} U_{L}}{m_{f} c_{f}} T_{a}(3)\right] \Delta t
\end{aligned}
$$




\subsection{Overnight heat loss coefficient}

In order to have a precise heat loss coefficient during night time, a separate overnight heat loss test is needed. The mathematical model of night heat loss is easy to obtain from Eq. (10) by eliminating the irradiance related terms and the draw off term which is shown as Eq. (15).

$$
m_{f} c_{f} \frac{d T_{f}}{d t}=-F^{\prime} U_{L}\left(T_{f}-T_{a}\right)
$$

The heat loss coefficient during night time can be calculated by solving Eq. (15) and the expression is shown in Eq. (16). $T_{f \text {-start }}$ and $T_{f \text {-end }}$ are the storage fluid temperatures at the start and end time of the overnight heat loss test. $T_{a(a v g)}$ is the average ambient temperature during the overnight heat loss test.

$$
F^{\prime} U_{L}=\frac{m_{f} c_{f}}{\Delta t} \ln \frac{T_{f-\text { start }}-T_{a(\mathrm{avg})}}{T_{f-\text { end }}-T_{a(\mathrm{avg})}}
$$

\subsection{Long term thermal performance prediction}

The SDHW storage average temperature can be calculated by Eq. (12), together with the given climate data $\left(G_{b}, G_{d}, T_{a}\right)$, the initial storage average temperature $T_{f}(0)$, the draw off flow rate $(F)$ and the supply cold fluid temperature $\left(T_{\text {main }}\right)$. Of course, the heat loss coefficient needs to be used separately during the day time and the night time.

The thermal performance can be obtained by calculating the storage energy change $Q$ before and after draw off process, see Eq. (17). $T_{f}$ and $T_{f}^{\prime}$ are the storage average temperatures before and after draw off process.

$$
Q=M_{f} c_{f}\left(T_{f}^{\prime}-T_{f}\right)
$$

\section{Thermal performance test method}

The thermal performance test method is designed based on the evaluating model and the thermal performance predicting model, together with a separate overnight heat loss coefficient test and the draw off load condition. 
The thermal performance test includes:

1. Model parameters tests.

The SDHW system is exposed to the sun for 12 hours in daytime - 6 hours before solar noon and 6 hours after solar noon. In the morning before the start of the experiment, the solar collector should be shielded from sunlight. The SDHW system was then filled with cold water or this can be prepared overnight in advance. The measurement starts immediately when the shielding was removed. Then the SDHW system operates normally for the whole day. During the day, the water temperature in the storage tank was measured and recorded every 30 to 60 minutes. This was done by a fully mixing process for the storage tank using a bypass circulation loop. When the temperature difference of the inlet and outlet of the circulation loop was less than $1 \mathrm{~K}$ in 10 minutes, the mean temperature of the inlet and outlet can be assumed as the mean water temperature of the storage tank. When a test ends, the solar collector needs to be shielded again from sunlight until the next test starts.

The total and diffuse solar irradiance on the collector surface, the ambient temperature, and the storage mean fluid temperatures should be recorded.

2. Overnight heat loss coefficient test.

The overnight heat loss coefficient test method is similar to the storage tank heat loss test of ISO 9459-2. The storage with a mean fluid temperature over $60{ }^{\circ} \mathrm{C}$ should be prepared. After cooling period during night, the storage fluid was mixed and the final mean fluid temperature can be obtained. The ambient temperature during test should also be recorded.

3. Draw off load condition

The draw off load condition for the new test method is flexible. It could be designed as an evening draw off like ISO 9459-2 or several times draw off per day at any time like 
ISO 9459-5. The flow rate of draw off and the cold water supply temperature should be recorded.

\section{Long term thermal performance prediction}

The long term thermal performance prediction can be calculated by knowing the SDHW's model parameters, the overnight heat loss coefficient, the climate data, the initial SDHW storage temperature, the draw off load profile and the cold water supply temperature. Then the storage temperature can be calculated at any time or time step by time step for the whole period. Usually, when the calculated storage temperature $T_{f}$ is over $100{ }^{\circ} \mathrm{C}$, the solar collector should be shielded $\left(G_{b}=0\right.$ and $\left.G_{d}=0\right)$ to avoid boiling water or when $T_{f}$ is lower than the cold water supply temperature $T_{\text {main, }}$, the draw off flow should stop to avoid useless thermal output. If there is a temperature limit for draw off, the draw off flow rate should also stop when $T_{f}$ is lower than the temperature limit to avoid unwanted low temperature draw off.

\section{Experimental verification}

\subsection{Test facilities}

The experimental verification for the evaluating and predicting model of a thermosyphon SDHW system was carried out in Beijing during a period from October to November 2012. The test platform was built according to ISO 9459-2. A schematic diagram of the test rig was shown in Fig. 3 while the main equipment was listed in Table 1. The thermosyphon solar water heater contains 18 evacuated tubes at $50^{\circ}$ tilted angle. The aperture area of the evacuated tubes is $2.61 \mathrm{~m}^{2}$. The volume of the storage tank is 190 Liter. The photograph of solar water heater was shown in Fig. 4. 


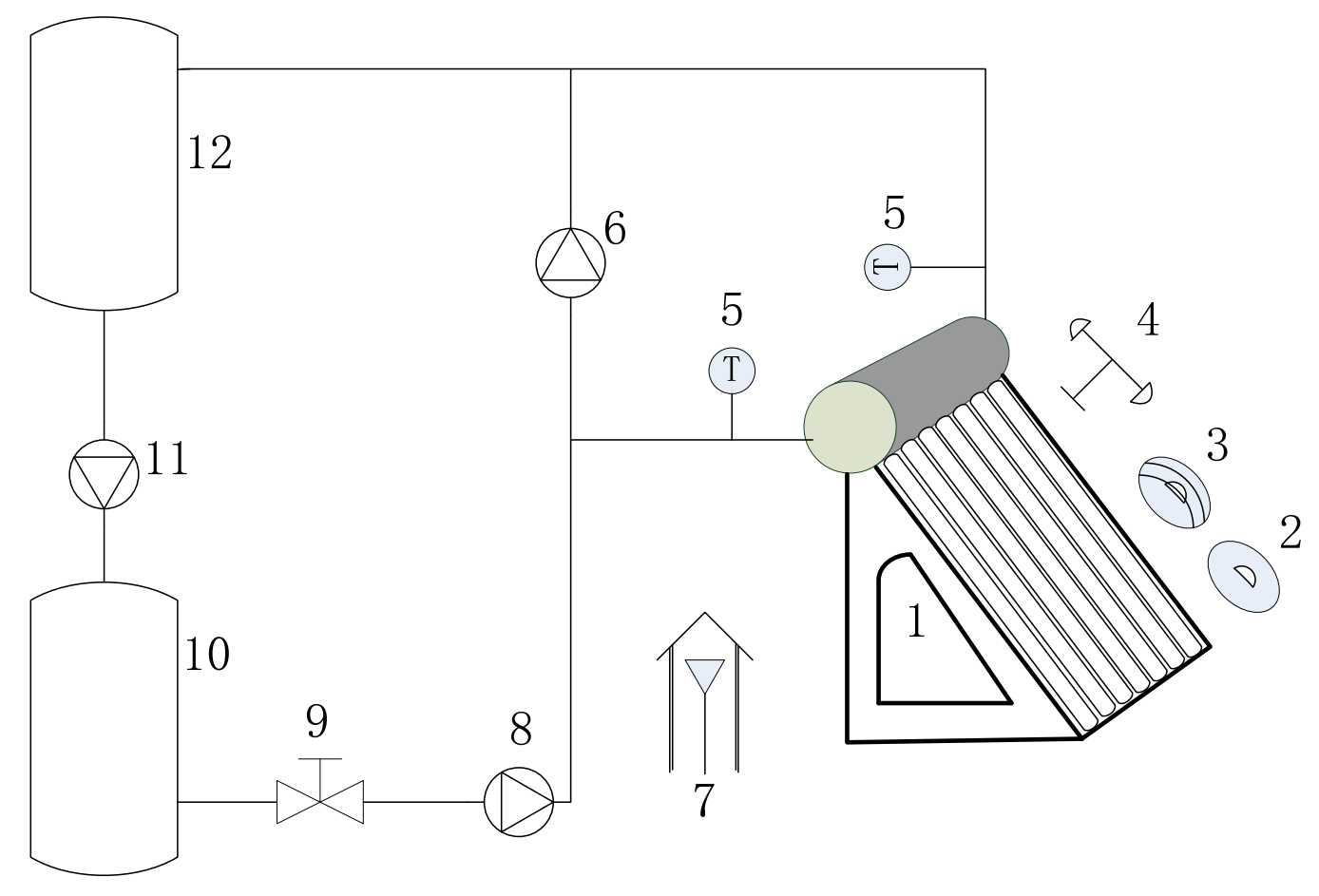

Fig. 3. Schematic diagram of the test platform

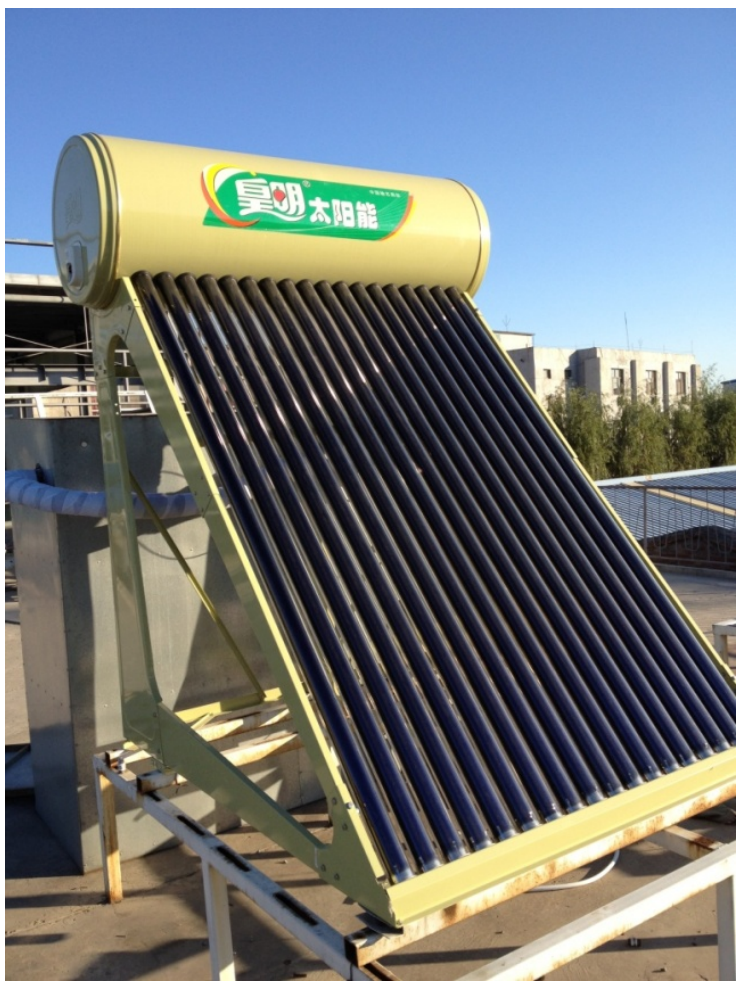

Fig. 4. Photograph of the solar water heater 


\begin{tabular}{llll}
\hline No. & Facility & No. & Facility \\
\hline 1 & Solar water heater & 7 & Ambient temperature sensor \\
2 & Pyranometer & 8 & Charging pump \\
3 & Pyranometer with shadow band & 9 & Electrically operated valve \\
4 & Anemometer & 10 & Constant temperature tank \\
5 & Temperature sensor & 11 & Feeding pump \\
6 & Mixing pump & 12 & Water storage tank \\
\hline
\end{tabular}

361

The constant temperature tank was well insulated and used for preparing water with a 363 certain temperature. Water was pumped to the SDHW system by the charging pump. After test, 364 the water in the SDHW system drained back to the water storage tank or can be pumped out by 365 the charging pump. There was a bypass circulating loop between the inlet and outlet of the 366 SDHW system which was used for mixing the water inside the storage tank. The PLC control 367 system was implemented to start and stop each electronic device in order to achieve different 368 control strategies.

\subsection{Model parameters regression}

370 The experimental data of four days (2012-10-25, 10-28, 10-31, 11-07) were used to 371 determine the model parameters. All the data processing, multi-linear regression [20] and 372 statistical analysis were carried out by R-tool software [22]. The evaluating mathematical model 373 of the SDHW system is Eq. (9). The results were shown in Table 2. 


\begin{tabular}{ccccc}
\hline Coefficients & Estimate & Standard error & $\mathbf{t}$ value & $\mathbf{P}(>|\mathbf{t}|)$ \\
\hline$F^{\prime}(\tau \alpha)_{e n}\left(0^{\circ}-10^{\circ}\right)$ & $4.52 \times 10^{-1}$ & $2.33 \times 10^{-2}$ & 19.39 & $<2 \times 10^{-16}$ \\
$F^{\prime}(\tau \alpha)_{e n}\left(10^{\circ}-20^{\circ}\right)$ & $5.10 \times 10^{-1}$ & $2.45 \times 10^{-2}$ & 20.83 & $<2 \times 10^{-16}$ \\
$F^{\prime}(\tau \alpha)_{e n}\left(20^{\circ}-30^{\circ}\right)$ & $4.41 \times 10^{-1}$ & $2.82 \times 10^{-2}$ & 15.68 & $<2 \times 10^{-16}$ \\
$F^{\prime}(\tau \alpha)_{e n}\left(30^{\circ}-40^{\circ}\right)$ & $5.35 \times 10^{-1}$ & $2.96 \times 10^{-2}$ & 18.08 & $<2 \times 10^{-16}$ \\
$F^{\prime}(\tau \alpha)_{e n}\left(40^{\circ}-50^{\circ}\right)$ & $5.86 \times 10^{-1}$ & $3.75 \times 10^{-2}$ & 15.64 & $<2 \times 10^{-16}$ \\
$F^{\prime}(\tau \alpha)_{e n}\left(50^{\circ}-60^{\circ}\right)$ & $5.13 \times 10^{-1}$ & $7.15 \times 10^{-2}$ & 7.17 & $3.26 \times 10^{-9}$ \\
$F^{\prime}(\tau \alpha)_{e n}\left(60^{\circ}-70^{\circ}\right)$ & $7.37 \times 10^{-1}$ & $1.54 \times 10^{-1}$ & 4.80 & $1.48 \times 10^{-5}$ \\
$F^{\prime}(\tau \alpha)_{e n}\left(70^{\circ}-80^{\circ}\right)$ & $7.06 \times 10^{-1}$ & $6.08 \times 10^{-1}$ & 1.16 & $2.51 \times 10^{-1}$ \\
$F^{\prime}(\tau \alpha)_{e n} K_{d}$ & $3.25 \times 10^{-1}$ & $9.30 \times 10^{-2}$ & 3.49 & $1.01 \times 10^{-3}$ \\
$F^{\prime} U_{L}$ & $9.54 \times 10^{-1}$ & $4.63 \times 10^{-1}$ & 2.06 & $4.43 \times 10^{-2}$ \\
$C_{b}$ & $4.30 \times 10^{2}$ & 94.7 & 4.54 & $3.56 \times 10^{-5}$ \\
\hline & & & & \\
\hline & & & & \\
\hline
\end{tabular}

379

380 The $R^{2}$ statistic value of the regression is 0.9771 indicating a satisfactory fitting of the 381 measured data by the model. From the results in Table 2 it can be seen that all the model 382 parameters are significant (|t value $\mid>2$ ). Only the efficiency under the transversal angle 383 between 70 and 80 degree is not significant which was caused by the low irradiance value and 384 limited data in that angle range.

\subsection{Predicting model verification}

Additional tests of the SDHW system were carried out in order to validate the predicting model. According to the model parameters in Table 2 and the predicting model of Eq. (11), the water temperatures in the storage at different time steps were calculated and compared with the measured values for the test days of 2012-10-30, 11-1 (half day) and 11-8. Table 3 to Table 5 listed the measured and predicted mean water temperature of the storage tank and the 
391 temperature difference together with other weather conditions. Fig. 5 to Fig. 7 show the 392 measured and predicted mean water temperature developing profile during one day as plot. $T_{p}$ 393 is the predicted water temperature and $T_{\text {diff }}$ is the difference between the measured and 394 predicted values.

Table 3 Comparison of the measured and predicted results 2012-10-30

\begin{tabular}{ccccccccc}
\hline $2012 / 10 / 30$ & $\begin{array}{c}\Delta t \\
(\mathrm{~s})\end{array}$ & $\begin{array}{c}\mathrm{G}_{\mathrm{b}} \\
\left(\mathrm{W} / \mathrm{m}^{2}\right)\end{array}$ & $\begin{array}{c}\mathrm{G}_{\mathrm{b}}{ }^{\prime} \\
\left(\mathrm{W} / \mathrm{m}^{2} \cdot \mathrm{s}\right)\end{array}$ & $\begin{array}{c}\mathrm{G}_{\mathrm{d}} \\
\left(\mathrm{W} / \mathrm{m}^{2}\right)\end{array}$ & $\begin{array}{c}\mathrm{T}_{\mathrm{a}} \\
\left({ }^{\circ} \mathrm{C}\right)\end{array}$ & $\begin{array}{c}\mathrm{T}_{\mathrm{f}} \\
\left({ }^{\circ} \mathrm{C}\right)\end{array}$ & $\begin{array}{c}\mathrm{T}_{\mathrm{p}} \\
\left({ }^{\circ} \mathrm{C}\right)\end{array}$ & $\begin{array}{c}\mathrm{T}_{\text {diff }} \\
\left({ }^{\circ} \mathrm{C}\right)\end{array}$ \\
\hline $7: 30$ & 0 & 0 & 0 & 0 & 0 & 22.4 & 22.4 & 0 \\
$8: 30$ & 3620 & 412.2 & 0.113866 & 29.0 & 4.9 & 24.4 & 24.1 & 0.28 \\
$9: 03$ & 1980 & 597.7 & 0.093683 & 41.4 & 7.5 & 26.3 & 26.0 & 0.30 \\
$9: 43$ & 2380 & 742.1 & 0.06069 & 48.3 & 8.5 & 29.1 & 28.7 & 0.36 \\
$10: 15$ & 1920 & 858.4 & 0.060534 & 54.6 & 9.0 & 31.6 & 30.8 & 0.70 \\
$10: 48$ & 1990 & 943.8 & 0.042911 & 60.8 & 9.5 & 34.0 & 33.3 & 0.68 \\
$11: 24$ & 2150 & 999.0 & 0.025687 & 64.1 & 10.0 & 36.9 & 36.7 & 0.14 \\
$11: 58$ & 2040 & 1054.1 & 0.027005 & 61.4 & 10.5 & 40.1 & 39.6 & 0.46 \\
$12: 30$ & 1940 & 1034.9 & -0.0099 & 69.0 & 10.9 & 42.9 & 42.5 & 0.42 \\
$13: 36$ & 3952 & 889.2 & -0.03686 & 89.0 & 11.5 & 48.2 & 48.3 & -0.09 \\
$14: 09$ & 2010 & 614.0 & -0.13689 & 112.3 & 12.1 & 50.6 & 50.3 & 0.27 \\
$14: 49$ & 2380 & 386.9 & -0.09544 & 130.4 & 12.1 & 52.5 & 52.1 & 0.33 \\
$15: 31$ & 2500 & 419.4 & 0.013007 & 91.9 & 12.5 & 54.5 & 53.8 & 0.60 \\
$16: 05$ & 2050 & 282.6 & -0.06673 & 55.9 & 12.3 & 55.7 & 54.7 & 0.94 \\
$16: 37$ & 1910 & 126.5 & -0.08172 & 35.2 & 11.8 & 56.2 & 55.2 & 0.96 \\
$17: 04$ & 1620 & 23.5 & -0.06362 & 13.9 & 11.3 & 56.1 & 55.1 & 0.98 \\
\hline
\end{tabular}

396

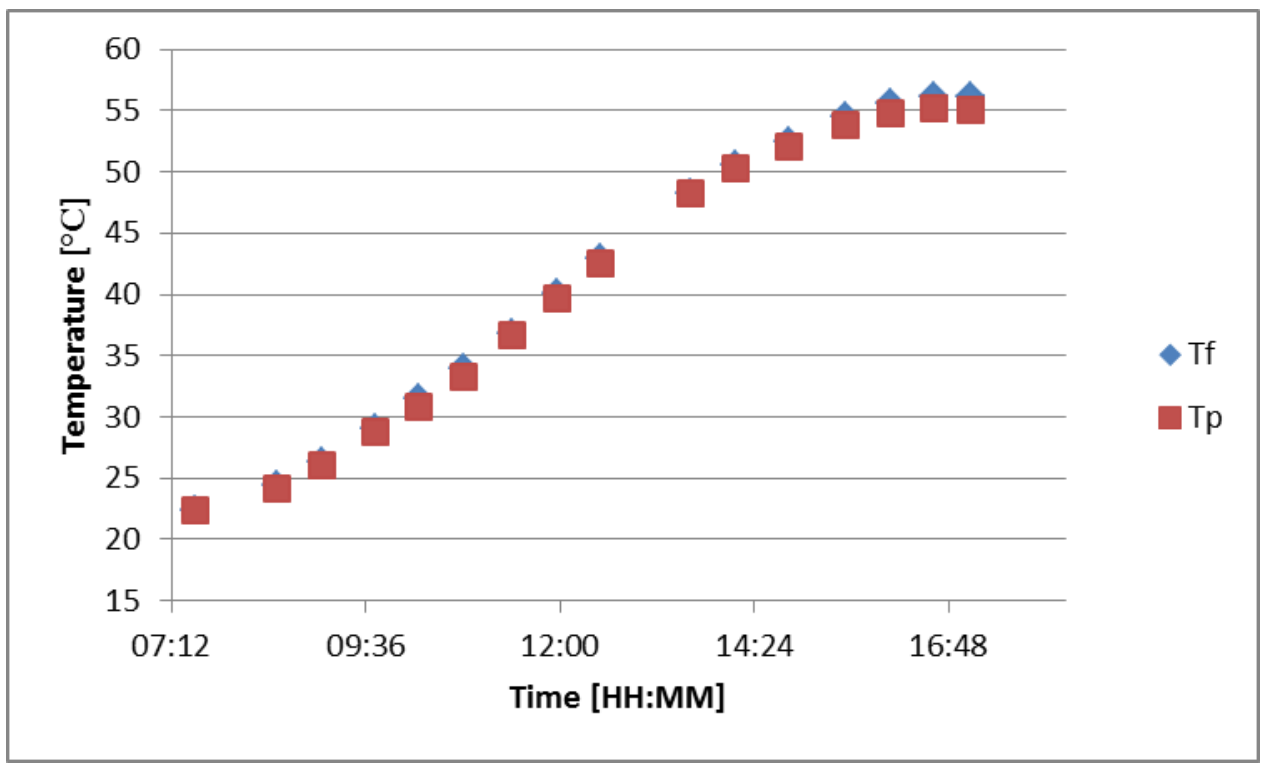

Fig. 5. Comparison of the measured and predicted water temperature 2012-10-30 
Table 4 Comparison of the measured and predicted results 2012-11-1

\begin{tabular}{ccccccccc}
\hline 2012/11/01 & $\begin{array}{c}\Delta \mathrm{t} \\
(\mathrm{s})\end{array}$ & $\begin{array}{c}\mathrm{G}_{\mathrm{b}} \\
\left(\mathrm{W} / \mathrm{m}^{2}\right)\end{array}$ & $\begin{array}{c}\mathrm{G}_{\mathrm{b}}{ }^{\prime} \\
\left(\mathrm{W} / \mathrm{m}^{2} \cdot \mathrm{s}\right)\end{array}$ & $\begin{array}{c}\mathrm{G}_{\mathrm{d}} \\
\left(\mathrm{W} / \mathrm{m}^{2}\right)\end{array}$ & $\begin{array}{c}\mathrm{T}_{\mathrm{a}} \\
\left({ }^{\circ} \mathrm{C}\right)\end{array}$ & $\begin{array}{c}\mathrm{T}_{\mathrm{f}} \\
\left({ }^{\circ} \mathrm{C}\right)\end{array}$ & $\begin{array}{c}\mathrm{T}_{\mathrm{p}} \\
\left({ }^{\circ} \mathrm{C}\right)\end{array}$ & $\begin{array}{c}\mathrm{T}_{\text {diff }} \\
\left({ }^{\circ} \mathrm{C}\right)\end{array}$ \\
\hline $08: 11$ & 0 & 285.1 & 0 & 41.2 & 3.0 & 40.6 & 40.6 & 0 \\
$08: 50$ & 2340 & 359.4 & 0.031767 & 45.8 & 4.0 & 41.7 & 41.6 & 0.06 \\
$09: 20$ & 1810 & 588.5 & 0.126547 & 57.3 & 7.2 & 43.3 & 43.2 & 0.08 \\
$09: 53$ & 1990 & 720.3 & 0.066264 & 62.9 & 8.5 & 45.4 & 45.3 & 0.05 \\
$10: 23$ & 1790 & 807.4 & 0.04863 & 69.8 & 9.9 & 47.6 & 47.1 & 0.46 \\
$10: 53$ & 1820 & 870.9 & 0.034882 & 73.8 & 11.2 & 49.9 & 49.5 & 0.33 \\
$11: 29$ & 2150 & 917.6 & 0.021743 & 78.4 & 12.3 & 52.8 & 52.5 & 0.22 \\
$12: 10$ & 2430 & 942.2 & 0.010113 & 79.2 & 13.5 & 56.3 & 55.6 & 0.66 \\
\hline
\end{tabular}

400

401

402

403

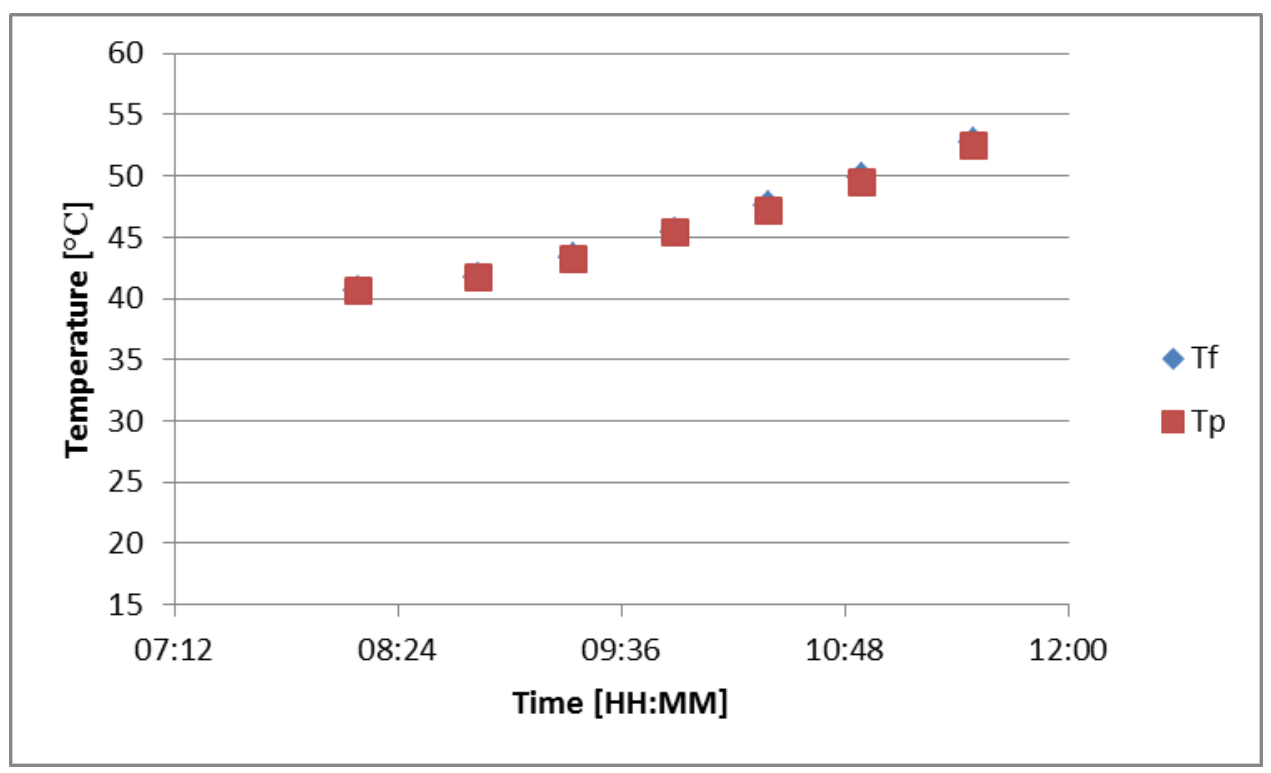

Fig. 6. Comparison of the measured and predicted water temperature 2012-11-1

Table 5 Comparison of the measured and predicted results 2012-11-8

\begin{tabular}{ccccccccc}
\hline $2012 / 11 / 08$ & $\begin{array}{c}\Delta \mathrm{t} \\
(\mathrm{s})\end{array}$ & $\begin{array}{c}\mathrm{G}_{\mathrm{b}} \\
\left(\mathrm{W} / \mathrm{m}^{2}\right)\end{array}$ & $\begin{array}{c}\mathrm{G}_{\mathrm{b}}{ }^{\prime} \\
\left(\mathrm{W} / \mathrm{m}^{2} \cdot \mathrm{s}\right)\end{array}$ & $\begin{array}{c}\mathrm{G}_{\mathrm{d}} \\
\left(\mathrm{W} / \mathrm{m}^{2}\right)\end{array}$ & $\begin{array}{c}\mathrm{T}_{\mathrm{a}} \\
\left({ }^{\circ} \mathrm{C}\right)\end{array}$ & $\begin{array}{c}\mathrm{T}_{\mathrm{f}} \\
\left({ }^{\circ} \mathrm{C}\right)\end{array}$ & $\begin{array}{c}\mathrm{T}_{\mathrm{p}} \\
\left({ }^{\circ} \mathrm{C}\right)\end{array}$ & $\begin{array}{c}\mathrm{T}_{\text {diff }} \\
\left({ }^{\circ} \mathrm{C}\right)\end{array}$ \\
\hline $07: 32$ & 0 & 0 & 0 & 0 & 0 & 52.7 & 52.7 & 0 \\
$08: 12$ & 2450 & 244.6 & 0.099857 & 39.7 & 3.0 & 52.3 & 53.0 & -0.74 \\
$08: 51$ & 2300 & 435.2 & 0.082852 & 55.2 & 5.0 & 52.8 & 54.4 & -1.63 \\
$09: 22$ & 1890 & 591.0 & 0.082422 & 65.4 & 7.1 & 54.25 & 55.9 & -1.67 \\
$09: 59$ & 2220 & 728.8 & 0.062086 & 71.5 & 9.1 & 56.65 & 58.3 & -1.62 \\
$10: 40$ & 2450 & 822.1 & 0.038074 & 83.3 & 10.7 & 59.8 & 60.7 & -0.94 \\
$11: 16$ & 2160 & 841.9 & 0.009151 & 102.6 & 11.5 & 62.55 & 63.5 & -0.96 \\
$11: 59$ & 2550 & 851.6 & 0.003818 & 113.4 & 12.5 & 65.35 & 66.4 & -1.07 \\
$12: 40$ & 2500 & 822.1 & -0.0118 & 120.5 & 13.2 & 69 & 69.2 & -0.20
\end{tabular}




\begin{tabular}{ccccccccc}
$13: 32$ & 3090 & 749.4 & -0.02352 & 117.0 & 13.7 & 72.85 & 72.8 & 0.08 \\
$14: 09$ & 2209 & 637.3 & -0.05076 & 107.9 & 13.7 & 75.3 & 74.6 & 0.68 \\
$14: 51$ & 2560 & 520.0 & -0.0458 & 97.4 & 13.7 & 77.7 & 76.7 & 1.03 \\
$15: 34$ & 2570 & 361.7 & -0.06161 & 74.1 & 13.8 & 79.45 & 77.9 & 1.52 \\
$16: 27$ & 3180 & 166.4 & -0.0614 & 43.0 & 13.4 & 80.1 & 78.7 & 1.36 \\
\hline
\end{tabular}

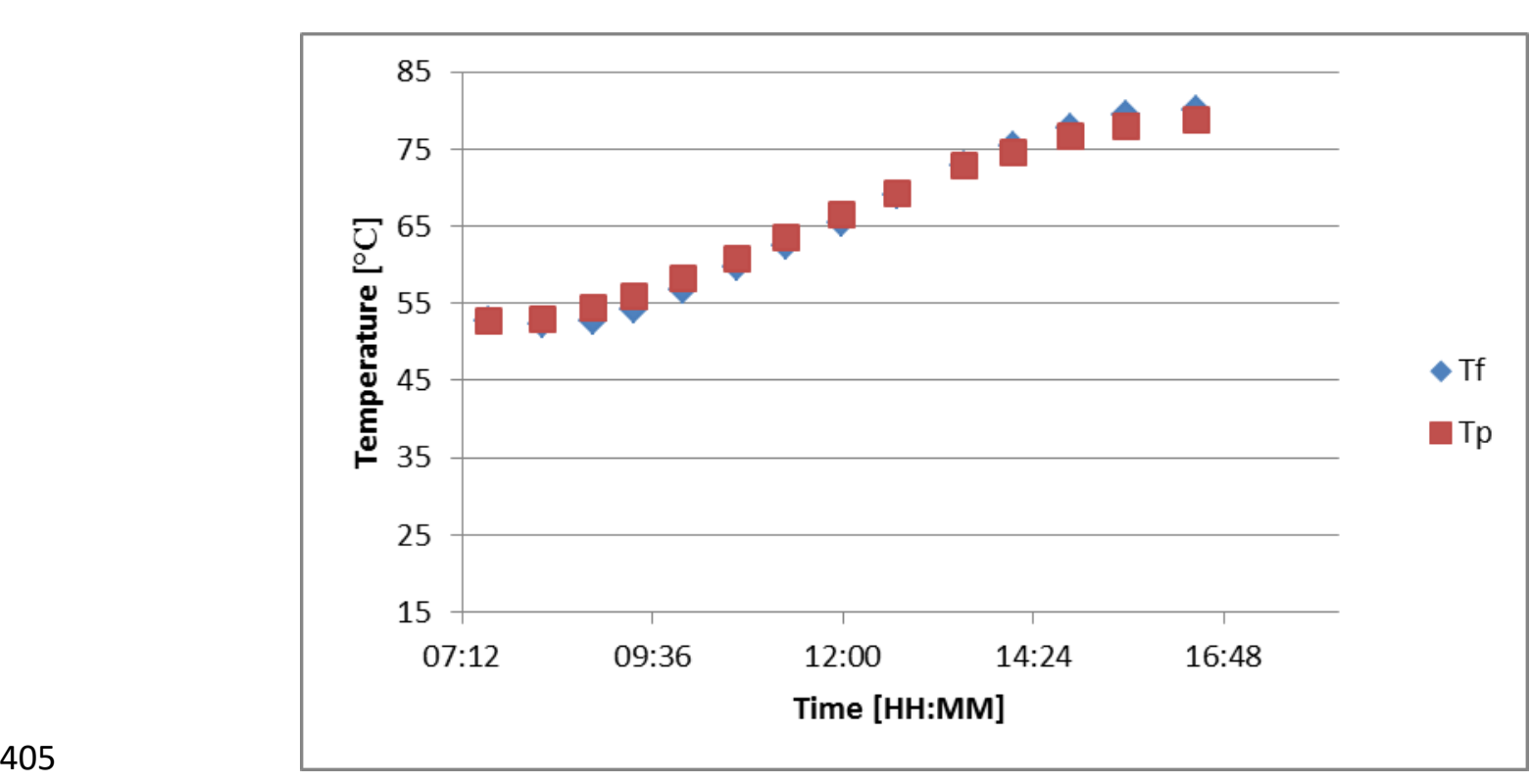

Fig. 7. Comparison of the measured and predicted water temperature 2012-11-8

407 The measured and predicted energy gain of the thermosyphon solar water heater for the 408 three days was also calculated and plotted in Fig. 8 together with the relative error. It can be 409 seen from the figure that all the relative error of three days energy gain was less than or equal 410 to $5 \%$ which shows a satisfactory accuracy of the predicting method. 


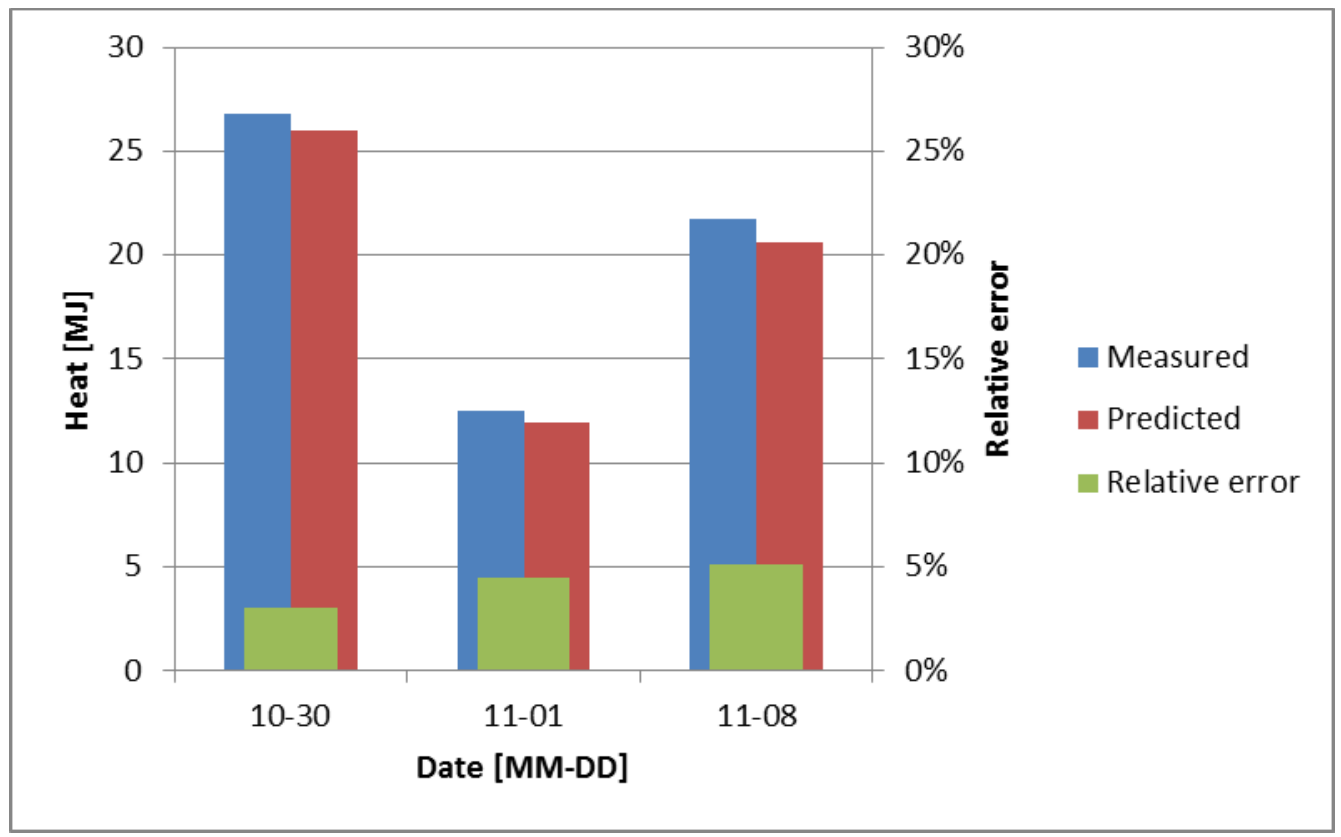

Fig. 8. Comparison of the measured and predicted energy gain in four days

413

414

415

416

417

418

419

420

421

422

423

424

425

426

427

\subsection{Overnight heat loss coefficient}

The overnight heat loss coefficient test was carried out during the night from 2012-11-7 to 2012-11-8. The calculated heat loss coefficient is $1.83 \mathrm{~W} / \mathrm{K}$.

\subsection{Annual thermal performance prediction}

The annual thermal performance prediction was calculated for the tested thermosyphon SDHW system under Beijing climate condition which was exported from TRNSYS 17 [23]. Two draw off load profiles were used. One is the evening draw off and the other is a three times draw off profile per day at $7 \mathrm{am}, 12 \mathrm{pm}$ and $18 \mathrm{pm}$. The total daily hot water consumption was set as 100 liter, 150 liter, 200 liter, 250 liter and 300 liter separately. The cold water supply temperature is $10{ }^{\circ} \mathrm{C}$ and the initial storage temperature is $20^{\circ} \mathrm{C}$. The draw off temperature limit is $10^{\circ} \mathrm{C}$.

The SDHW system storage temperature was calculated hour by hour for the whole year. Then the energy output by draw off process was calculated and added together as the annual thermal performance which is shown in Fig. 9. It can be seen from Fig. 9 that the annual thermal performance of the SDHW system is increasing as the increase of the daily hot water 
428

429

430 consumption. The evening draw off load condition can obtain higher energy output than the three times draw off load condition. The annual energy output by loading the evening draw off reached the highest at the daily hot water consumption around 250 liter while the annual energy output by loading three time draw off per day was increasing and didn't reach peak as the daily hot water consumption increased to 300 liter.

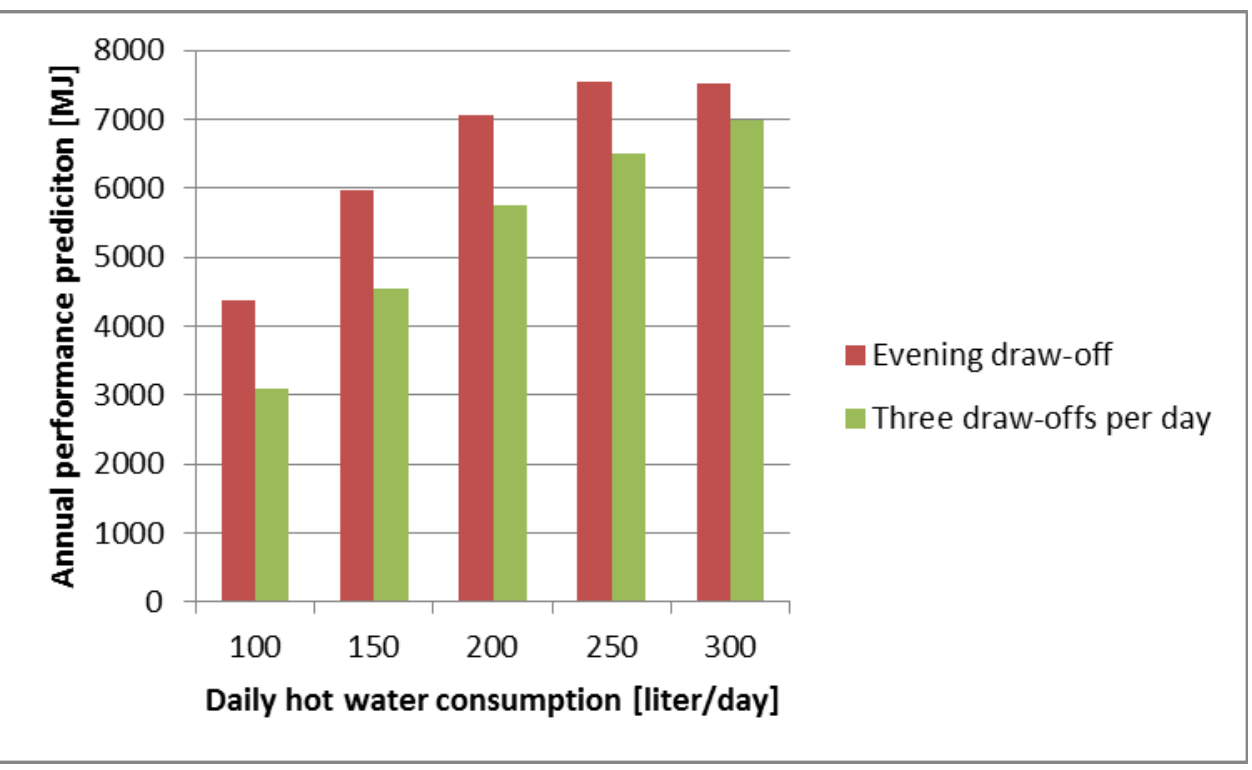

Fig. 9. Annual thermal performance prediction at Beijing

\subsection{Discussion}

According to the results comparison in section 4.3 it can be seen that the difference of the measured and predicted mean water temperature in the storage tank was maximum $1.36{ }^{\circ} \mathrm{C}$ and minimum $0.66{ }^{\circ} \mathrm{C}$ after testing and the relative error of energy gain is within $5 \%$. The deviation was relatively small for the whole day testing which demonstrates that this new method is valid for predicting the thermal performance for thermosyphon SDHW system. However, in theory the accuracy could be further improved if the transversal angle resolution could be even smaller for example $5^{\circ}$ or the mixing process could be carried out strictly according to the transversal angle range for example doing the mixing process when the transversal angle changed to $10^{\circ}, 20^{\circ}, 30^{\circ} \ldots . . .80^{\circ}$. The transversal angle can be calculated in 
advance based on the testing date and test facility before experiment. So it is recommended to calculate the exact time of doing the mixing process in advance.

According to the deviation analysis of the temperature increase during one day's test, it is found that the largest error always comes from the beginning period in the morning and the closing period in the late afternoon. The relative large deviation can be explained by the influence of the solid thermal capacitance. It is a common problem when predicting a whole day or some continuous days' temperature, such as a collector field in TRNSYS. The predicted temperature in such period usually had high deviation compared to actual temperature. According to our experiences, the separated solid thermal capacitance method is the best choice compared with other techniques.

The mixing operation was carried out several times during one day. It is needed for the evaluating test but not necessary for the predicting test in practical use. The purpose of doing multi mixing operation is just to show the temperature comparison profile of the mean fluid temperature in the storage tank for the whole day. The mixing experimental method can give accurate measurement of the mean fluid temperature in storage tank. But it needs relatively long time before a uniform tank temperature is achieved. To some extent, the mixing action could break the natural convection process of fluid between the tubular collector tubes and the storage tank by accelerating the fluid velocity and the heat transfer. Therefore if only the final fluid temperature were measured, the predicting accuracy could be better.

Compared to the $Q-H$ test method adopted by ISO 9459-2, the new test method has several advantages. First, the mathematical model of the new test method describes the detailed heating, cooling and draw off processes of thermosyphon SDHW system which is more accurate than the "black box" model of the $Q-H$ test method. Then, the model parameters of the new test method have clear physical meaning. Third, the $Q-H$ test method can only have evening draw off load condition while the new test method can carry out complex draw off load profiles.

Compared to the dynamic system method adopted by ISO 9459-5, the mathematical model of the new test method is simpler and easier to understand. Then, users of the new test 
472 method can easily develop their own calculation based on the equations provided by this paper

473 without buying the calculation software.

\section{Conclusions}

475 A test method for evaluating and predicting the thermal performance of thermosyphon 476 SDHW systems was proposed. The evaluating mathematical model was developed based on the 477 two-node theory which is widely used in solar collector testing area. The model parameters 478 derived in the evaluating equation have clear physical meaning and can be obtained by experiments. An analytical expression of the mean fluid temperature in storage tank was derived by using the Laplace transformation treatment for the evaluating mathematical model. The predicting equation of the mean fluid temperature can be used to predict the thermal performance of SDHW system. Thermal performance experimental method was designed for the new test method. The experimental verification for a thermosyphon SDHW system was carried out at a standard test platform in Beijing. Test data of four days were used for determining the evaluating model parameters while the rest of the test data were used to predict the system's storage temperature. The predicted mean fluid temperatures in the storage tank were compared with the measured temperatures. The deviations between the measured and predicted results were analyzed. The results showed that the difference between the measured and the predicted temperature was maximum $1.4^{\circ} \mathrm{C}$ at the end of one day test and the relative error of energy gain after whole testing was within $5 \%$ which demonstrated that the new method can accurately predict the thermal performance of

492 thermosyphon SDHW system. Possible reasons of the prediction deviation were discussed. 493 Feasible suggestions were recommended for future improvement such as increase transversal 494 angle resolution and carry out the mixing process strictly according to the transversal angles. 495 The annual thermal performance prediction was calculated for the tested SDHW system under 496 Beijing climate condition and two draw off load profiles at different daily hot water 497 consumptions. The proposed test method was compared to the standard test methods ISO 498 9459-2 and ISO 9459-5. 
Future works will focus on the improvement of the test method and the extended application to forced or other SDHW systems.

\section{Reference}

502 [1] N. V Ogueke, E.E. Anyanwu, O. V Ekechukwu, A review of solar water heating systems, J. Renew. Sustain. Energy. 1 (2009) 21. doi:10.1063/1.3167285.

[2] J.A. Duffie, W.A. Beckman, Solar Engineering of Themal Processes. Second Edition, John Wiley \& Sons, INC, 1991.

506

[3] D.A.G. Redpath, Thermosyphon heat-pipe evacuated tube solar water heaters for 507

508

509

510 northern maritime climates, Sol. Energy. 86 (2012) 705-715. doi:10.1016/j.solener.2011.11.015.

[4] T.T. Chow, Z.T. Dong, L.S. Chan, K.F. Fong, Y. Bai, Performance evaluation of evacuated tube solar domestic hot water systems in Hong Kong, Energy Build. 43 (2011) 3467-3474. doi:10.1016/j.enbuild.2011.09.009.

512 [5] G.L. Morrison, I. Budihardjo, M. Behnia, Measurement and simulation of flow rate in a 513 water-in-glass evacuated tube solar water heater, Sol. Energy. 78 (2005) 257-267. doi:10.1016/j.solener.2004.09.005.

515 [6] W. Spirkl, J. Muschaweck, General-Model for Testing Solar Domestic Hot Water-Systems, 516 Sol. Energy Mater. Sol. Cells. 28 (1992) 93-102.

517 [7] W. Spirkl, Dynamic solar domestic hot water testing, J. Sol. Energy Eng. 112 (1990) 98.

518 [8] ISO 9459-2 Solar heating -Domestic water heating systems Part 2: Outdoor test methods 519 for sysytem performance characterization and yearly performance prediction of solaronly systems, (1995).

521 [9] CNS B 7277:No.12558-1989. Method of test of solar water heaters, (1989).

522 [10] B. Perers, H. Zinko, P. Holst, Analytical model for the daily energy input/output 
relationship for solar collector systems ISBN 91-540-4359-X, Swedish Council for Building Research, 1985.

[11] ISO 9459-5 Solar heating-Domestic water heating systems-Part 5: system performance characterization by means of whole-system tests and computer simulation, (2007).

[12] E. Kaloudis, Y.G. Caouris, E. Mathioulakis, V. Belessiotis, Comparison of the dynamic and input-output methods in a solar domestic hot water system, Renew. Energy. 35 (2010) 1363-1367. doi:10.1016/j.renene.2009.11.007.

[13] S. V Joshi, R.S. Bokil, J.K. Nayak, Test standards for thermosyphon-type solar domestic hot water system: review and experimental evaluation, Sol. Energy. 78 (2005) 781-798. doi:10.1016/j.solener.2004.08.023.

[14] B.J. Huang, Performance rating method of thermsiphon solar water heaters, Sol. Energy. 50 (1993) 435-440. doi:10.1016/0038-092x(93)90065-v.

[15] In situ Scientific Software. Dynamic System Testing Program (Version 2.6). ISS,Kriegerstr. 23d, D-82110 Germering, (1996).

[16] W. Kong, Z. Wang, J. Fan, P. Bacher, B. Perers, Z. Chen, et al., An improved dynamic test method for solar collectors, Sol. Energy. 86 (2012) 1838-1848.

[17] W. Kong, Z. Wang, J. Fan, B. Perers, Z. Chen, S. Furbo, et al., Investigation of thermal performance of flat plate and evacuated tubular solar collectors according to a new dynamic test method, in: Energy Procedia, Elsevier BV, 2012: pp. 152-161.

[18] H.J. Hou, A transient test method for thermal performance of flat-plate solar collectors, Acta Energiae Solaris Sin. (2004) 310-314.

[19] W. Kong, Z. Wang, X. Li, X. Li, N. Xiao, Theoretical analysis and experimental verification of a new dynamic test method for solar collectors, Sol. Energy. 86 (2012) 398-406.

[20] S. Fischer, W. Heidemann, H. Muller-Steinhagen, B. Perers, P. Bergquist, B. Hellstrom, Collector test method under quasi-dynamic conditions according to the European 
Standard EN 12975-2, Sol. Energy. 76 (2004) 117-123. doi:DOI

550 [21] W. Kong, B. Perers, J. Fan, S. Furbo, F. Bava, A new Laplace transformation method for 551 dynamic testing of solar collectors, Renew. Energy. 75 (2015) 448-458. doi:10.1016/j.renene.2014.10.026.

[22] R Development Core Team R: A language and environment for statistical computing. $\mathrm{R}$ Foundation for Statistical Computing, Vienna, Austria. ISBN 3-900051-07-0, URL http://www.R-project.org/, (2011).

[23] S.A. Klein. et al, TRNSYS 17: A Transient System Simulation Program. Solar Energy Laboratory, University of Wisconsin, Madison, USA, (2012). http://sel.me.wisc.edu/trnsys.

558 